\title{
JUSTICE, TRUST, AND TRUSTWORTHINESS: A LONGITUDINAL ANALYSIS INTEGRATING THREE THEORETICAL PERSPECTIVES
}

\author{
JASON A. COLQUITT \\ JESSICA B. RODELL \\ University of Georgia
}

\begin{abstract}
Despite a significant amount of theoretical and empirical attention, the connection between justice and trust remains poorly understood. Our study utilized Mayer, Davis, and Schoorman's (1995) distinction between trustworthiness (the ability, benevolence, and integrity of a trustee) and trust (a willingness to be vulnerable to the trustee) to clarify that connection. More specifically, we drew on a theoretical integration of social exchange theory, the relational model, and fairness heuristic theory to derive predictions about the relationships among justice, trustworthiness, and trust, with supervisors as the referent. A longitudinal field study stretching over two periods showed that informational justice was a significant predictor of subsequent trust perceptions, even when analyses controlled for prior levels of trust and trustworthiness. However, the relationship between justice and trustworthiness was shown to be reciprocal. Procedural and interpersonal justice were significant predictors of subsequent levels of benevolence and integrity, with integrity predicting subsequent levels of all four justice dimensions. We describe the theoretical implications of these results for future research in the justice and trust literatures.
\end{abstract}

Scholarly interest in the topics of organizational justice and trust has exploded in the past several years, as evidenced by the increased attention these topics have received in organizational journals. One likely reason for that increased attention is that justice perceptions and trust assessments are consistent predictors of employee attitudes and behaviors. For example, meta-analytic results support a relationship between justice perceptions and key organizational outcomes, including organizational commitment, task performance, and citizenship behavior (Cohen-Charash \& Spector, 2001; Colquitt, Conlon, Wesson, Porter, \& Ng, 2001). Meta-analyses have also linked trust assessments to similar outcomes, such as task performance, citizenship behavior, and counterproductive behavior (Colquitt, Scott, \& LePine, 2007; Dirks \& Ferrin, 2002).

Organizational justice refers to perceptions of fairness in decision-making and resource allocation environments (Greenberg, 1987) and is commonly divided into four dimensions. Distributive justice refers to the fairness of decision outcomes, and individuals judge it by determining whether the perceived ratio of outcomes to inputs matches those of a comparison other (Adams, 1965), or

Editor's note: The manuscript for this article was accepted for publication during the term of $A M J$ 's previous editor-in-chief, Duane Ireland. whether resource allocations match appropriate norms (Leventhal, 1976). Procedural justice refers to the perceived fairness of decision-making procedures (Leventhal, 1980; Thibaut \& Walker, 1975). Procedures are evaluated by their level of consistency, bias suppression, accuracy, correctability, ethicality, and the degree to which they allow voice and input (Leventhal, 1980; Thibaut \& Walker, 1975). Interactional justice refers to the fairness of interpersonal treatment during decision-making procedures (Bies \& Moag, 1986). Interactional justice can be further divided into interpersonal and informational components. Interpersonal justice reflects the degree of respect and propriety authority figures use when implementing procedures, and informational justice reflects the degree of justification and truthfulness offered during procedures (Colquitt, 2001; Greenberg, 1993).

The definition of trust has been much debated in the literature (Rousseau, Sitkin, Burt, \& Camerer, 1998). Some scholars have defined trust as confident, positive expectations regarding a trustee's conduct, motives, and intentions in situations entailing risk (e.g., Cook \& Wall, 1980; Gabarro \& Athos, 1976; Lewicki \& Bunker, 1995). Those confident, positive expectations create a willingness to act on the basis of the words, actions, and decisions of the trustee (Cook \& Wall, 1980; McAllister, 1995). Measures of this conceptualization of trust operationalize those confident, positive expecta- 
tions by asking respondents whether trustees are competent, skilled, efficient, caring, loyal, principled, and fair (Cook \& Wall, 1980; Gabarro \& Athos, 1976; McAllister, 1995; Nyhan \& Marlowe, 1997; Roberts \& O'Reilly, 1974).

Mayer and colleagues' (1995) model of trust offers a different definition. These authors defined trust as the willingness to be vulnerable to the actions of a trustee on the basis of the expectation that the trustee will perform a particular action, irrespective of any monitoring or control mechanisms (see also Schoorman, Mayer, \& Davis, 2007). Measures of this conceptualization of trust operationalize that willingness to be vulnerable by asking respondents about their willingness to allow a trustee to have significant influence over their working lives (Mayer \& Davis, 1999; Mayer \& Gavin, 2005; Schoorman et al., 2007). Importantly, Mayer and colleagues (1995) argued that some of the same concepts that are typically assessed in the confident, positive expectations approach predict trust as they define it. In changing the relevant time horizon from one represented by future-oriented expectations to one captured in current state assessments, Mayer and colleagues (1995) framed the concepts as facets of trustworthiness-attributes or characteristics of a trustee that inspire trust. Ability reflects concepts such as competence, skills, efficiency, and dedication. Benevolence reflects the sense that the trustee wants to "do good" to the truster, with "doing good" including concepts such as being caring and open. Integrity reflects an ad- herence to a set of acceptable principles or a set of shared values.

A number of theoretical perspectives include arguments for significant relationships among justice and trust concepts. These include social exchange theory (Blau, 1964), the relational model (Lind \& Tyler, 1988; Tyler \& Lind, 1992), and fairness heuristic theory (Lind, 2001; Van den Bos, 2001). A narrative review by Lewicki, Wiethoff, and Tomlinson noted that "the volume of both theoretical and empirical work over the last 15 years clearly points to a strong relationship between trust and justice" (2005: 253). Meta-analyses in both literatures have also pointed to moderately to strongly positive correlations among justice and trust concepts (CohenCharash \& Spector, 2001; Colquitt et al., 2001; Dirks \& Ferrin, 2002). Nevertheless, Lewicki and colleagues also noted that "in spite of the presumed connections between justice and trust in theory and practice, the precise association between these constructs has not been fully elaborated" (2005: 248). The authors further argued that "continued efforts to tease apart the two constructs and understand the nature of their connectedness will require a great deal of careful conceptual thinking and linguistic precision, no less the challenge of actually calibrating these relationships through empirical research" (Lewicki et al., 2005: 265).

Figure 1 summarizes the conventional wisdom on the justice-trust connection as it currently exists in the literature. In our view, that conventional wisdom is deceptively uncontroversial, masking

FIGURE 1

The Conventional Wisdom on the Justice-Trust Connection

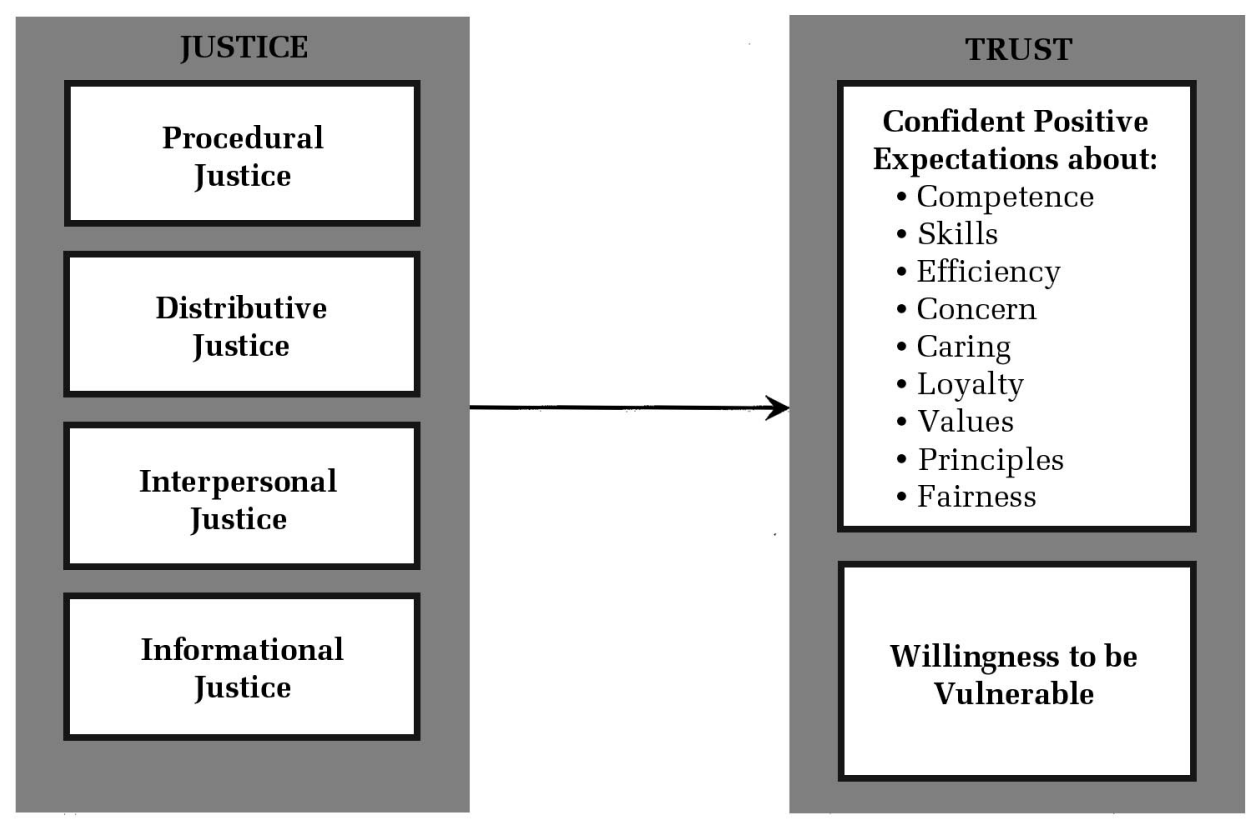


four distinct questions. First, it may be that justice is more highly related to some expectations than others, as expectations about competence or skills could have different nomological networks than expectations about concern or values. Second, it may be that estimates of the relationship between justice and confident, positive expectations have been inflated because those expectations often allude to fairness. Appendix A cites the 13 studies that have integrated justice and trust using established measures of confident, positive expectations. Four of the five measures explicitly contain fairness content (Cook \& Wall, 1980; Gabarro \& Athos, 1976; Nyhan \& Marlowe, 1997; Roberts \& O'Reilly, 1974). Third, it remains unclear whether justice is even related to the willingness to be vulnerable, because past research has rarely connected justice to that concept. Fourth, some theoretical perspectives frame concepts such as concern, loyalty, values, and principles as antecedents of justice, not consequences of it (Lind \& Tyler, 1988; Tyler, 1989, 1994; Tyler \& Lind, 1992), implying that the causal order in Figure 1 is either incorrect or oversimplified.

With those issues in mind, we sought in this study to clarify the relationship between justice and trust. A central premise of our study is that Mayer and colleagues' (1995) distinction between trustworthiness and trust can bring increased conceptual and operational precision to our understanding of the justice-trust connection. For this reason, our study adopts Mayer and colleagues' willingness to be vulnerable definition for trust, as opposed to the confident, positive expectations definition used by other scholars (Cook \& Wall, 1980; Gabarro \& Athos, 1976; Lewicki \& Bunker, 1995). Conceptually speaking, Mayer and colleagues' ability, benevolence, and integrity dimensions reposition the concepts commonly assessed in the confident, positive expectations approach into the three facets of trustworthiness. Figure 2 reflects this repositioning, with concepts such as competence, concern, values, and so forth now represented by the ability, benevolence, and integrity boxes in the new diagram. That repositioning allows for the possibility that the justicetrust relationship differs in nature from the justicetrustworthiness relationship. Operationally speaking, the scales used to measure Mayer and colleagues' (1995) concepts do not include fairness content to the same degree, providing the linguistic precision that Lewicki and colleagues (2005) called for in their discussion of the justice-trust connection. Fairness is included only in Mayer and colleagues' integrity facet, not in the ability, benevolence, or trust measures.
In addition to drawing on Mayer and colleagues' (1995) model, the repositioning in Figure 2 represents an integration of social exchange theory (Blau, 1964), the relational model (Lind \& Tyler, 1988; Tyler \& Lind, 1992), and fairness heuristic theory (Lind, 2001; Van den Bos, 2001). Specifically, we argue that social exchange theory suggests that justice acts as an antecedent of the willingness to be vulnerable, reflecting a justice to trust causal flow. In contrast, the relational model and fairness heuristic theory contain propositions more relevant to the relationship between justice and trustworthiness concepts. Moreover, their predictions for those relationships are contradictory. The relational model seems to predict a trustworthiness to justice causal flow, whereas fairness heuristic theory seems to predict a justice to trustworthiness ordering. These two theories can therefore be used to predict that the relationships between justice and trustworthiness concepts will be reciprocal or nonrecursive.

We believe that our examination of the structure in Figure 2 can remove some of the theoretical muddiness that currently plagues the literature on justice and trust and that this effort will have important theoretical and practical implications. Theoretically speaking, the muddiness prevents scholars from operationalizing variables in a manner that is consistent with a given theory. For example, our integration will show that social exchange theory focuses specifically on the willingness to be vulnerable, whereas the relational model focuses specifically on the concepts reflected in trustworthiness (Blau, 1964; Organ, 1990; Tyler, 1989, 1994). Failing to account for these nuances results in inappropriate applications of those theories and potentially inaccurate portrayals of causal order and endogeneity. That muddiness also results in unnecessarily coarse theorizing, preventing scholars from drawing distinctions between constructs that may have differing relationships with justice, such as ability versus benevolence and integrity.

Practically speaking, this muddiness can lead to managerial implications that are incomplete or unfounded. For example, if employees have already formed perceptions of trustworthiness, will justicerelevant actions on the part of managers continue to predict intentions to accept vulnerability? As another example, which should managers focus more of their time on? Being distributively fair, procedurally fair, interpersonally fair, or informationally fair? Or is more gained by promoting a sense of ability or a sense of benevolence and integrity? A deeper level of theoretical nuance is needed to be able to convey to managers the most promising route for building a willingness to be vulnerable in 
FIGURE 2

A More Nuanced Model Utilizing a Mayer and Colleagues (1995) Lens

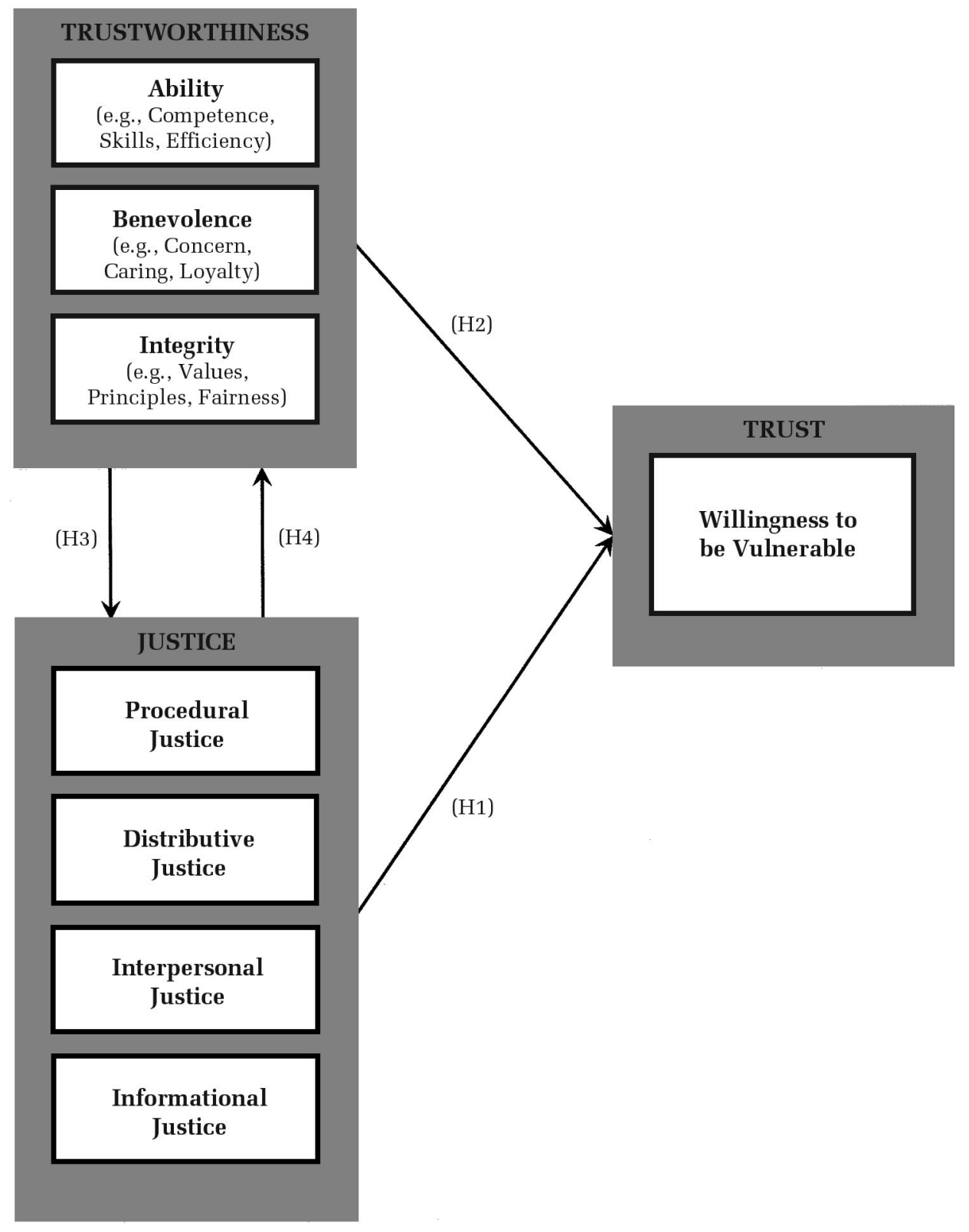

their units. Attaining that level of nuance requires the simultaneous operationalization over time of trustworthiness, justice, and willingness to be vulnerable.

\section{THEORY AND HYPOTHESES}

The sections to follow review the theoretical perspectives relevant to the connections in Figure 2, along with representative empirical tests of those perspectives. We begin by focusing on the paths involving trust before moving on to the relationship between justice and trustworthiness. We then offer the specific hypotheses that were tested in a twoperiod longitudinal field study that used supervisors as the referent for justice, trustworthiness, and trust. George and Jones (2000) suggested that time should become a more central element in scholarly theorizing and that the time lags used in longitudinal research should be based on sound conceptual logic. In particular, they suggested that scholars should apply time concepts to the conceptualization of constructs (e.g., how are the past, present, and future represented in a construct, how stable is it, how are experiences with it aggregated or bracketed in one's mind?) and to the description of rela- 
tionships (e.g., do perceived causes have immediate or delayed effects, what time aggregations are appropriate for observing effects?). With these recommendations in mind, we draw attention to the role of time in the theorizing that supports our hypotheses.

\section{Predicting Trust: Social Exchange Theory}

Figure 2 casts both trustworthiness and justice as predictors of trust. The relationship between justice and trust has most often been described using social exchange theory (Blau, 1964), which summarizes how the transactions in an exchange relationship evolve and change over time. Conceptualizations of exchange theory have stressed that a number of resources can be involved in exchanges. For example, Foa and Foa (1980) identified six classes of resources-love, status, information, money, goods, and services-that could be contrasted on two dimensions: particularism and concreteness. Particularism reflects how significant the provider of a resource is to the meaning and value of the resource; status and services are more particular, and money and goods are more universal. Concreteness reflects whether a resource is overtly tangible or more symbolic; goods and services are more concrete, and status and information are more symbolic.

Blau's (1964) conceptualization of exchange theory distinguishes between economic exchange relationships, which are based on strict, quid pro quo exchanges, and social exchange relationships, which are based on long-term and unspecified exchanges of tangible and intangible obligations. He provided several examples of intangible resources, including acceptance, compliance, advice, assistance, and support, all of which are similar to Foa and Foa's (1980) status and information. Consider a circumstance in which a supervisor provides assistance and support to an employee. The social exchange theory argument is that these rewarding actions obligate the employee to reciprocate in kind (see also Gouldner, 1960). To discharge that obligation, the employee could reciprocate with acceptance and compliance, or even with his/her own brand of assistance and support.

Blau described the importance of trust in social exchanges: "Since there is no way to assure an appropriate return for a favor, social exchange requires trusting others to discharge their obligations" (1964: 94). In the example given above, neither the supervisor nor the employee can be absolutely certain that their actions are going to be met with reciprocated benefits, because no formal contract governs such events. Fortunately, Blau ar- gued that "the gradual expansion of exchange transactions promotes the trust necessary for them" (1964: 98). In this way, the assistance and support the supervisor provided promotes trust on the part of the employee, making the employee more willing to reciprocate. Blau's (1964) description of trust seems quite similar to Mayer and colleagues' (1995) willingness to be vulnerable, as it implies accepting vulnerability on the basis of the expectation that an action will occur irrespective of monitoring or safeguards.

Blau's (1964) arguments were not applied to justice concepts until Organ's (1990) analysis of motives for engaging in citizenship behavior. Organ suggested that fair actions on the part of a supervisor could themselves comprise the sort of rewarding actions that engender reciprocation, one form of which would be citizenship behavior. That proposition suggests that equity, consistency, bias suppression, voice, respect, and justification are functionally similar to exchange currencies such as status, information, acceptance, compliance, advice, assistance, and support (Blau, 1964; Foa \& Foa, 1980). Along these lines, Konovsky and Pugh (1994) suggested that justice can increase the acceptance of vulnerability because it signals how decision making will proceed over the long term. If an authority has adhered to justice rules before, the "default view" is often that they will do so again (Brockner \& Siegel, 1995).

In their review, Cropanzano and Mitchell (2005) argued that trust is a promising mechanism for explaining the social exchange benefits of justice and other related behaviors, though empirical tests have been sparse. In fact, the relationship between justice and the willingness to be vulnerable form of trust remains unclear, because past research has tended to rely on measures based on the confident, positive expectations form (e.g., Aryee, Budhwar, \& Chen, 2002; Konovsky \& Pugh, 1994). It also remains unclear whether justice predicts the willingness to be vulnerable when considered simultaneously with trustworthiness, as in Figure 2. Colquitt et al. (2007) suggested that some facets of trustworthiness could themselves be viewed as currencies capable of fostering a social exchange. That assertion suggests that concern, loyalty, shared values, principles, and so forth are also functionally similar to the exchange currencies of status, information, acceptance, compliance, advice, assistance, and support (Blau, 1964; Foa \& Foa, 1980).

If justice and trustworthiness are viewed as signals for employees to trust their supervisor, how long does it take for these signals to impact the willingness to accept vulnerability? Drawing a bridge to the attitude-behavior literature (Azjen, 
1991; Azjen \& Fishbein, 1980), we suggest that trust reflects a behavioral intention to be vulnerable, whereas trustworthiness and justice reflect attitudes toward a supervisor. As with other behavioral intentions, employees' intentions to be vulnerable likely result from a deliberate process wherein they carefully consider relevant information (Azjen, 1991; Azjen \& Fishbein, 1980), such as trustworthiness and trust. The controlled and cognitive nature of this process suggests that employees need enough separation in time between supervisory actions and trust intentions to evaluate the relevant information. Although this length of time may vary among individuals and situations, it is bounded by the opportunity to experience repeated interactions with supervisors that provide justice and trustworthiness information (Cropanzano, Byrne, Bobocel, \& Rupp, 2001; Mayer et al., 1995).

Moving beyond issues of time frame, how can one draw predictions about the unique effects of justice and trustworthiness on trust, given their similar positioning in exchange theorizing? One way is to consider the specific concepts encompassed by the justice and trustworthiness dimensions to gauge whether those concepts are uniquely relevant to the willingness to be vulnerable. To the extent that it even is an exchange currency, ability seems to represent one that is much different from the other trustworthiness dimensions and the justice dimensions. In Foa and Foa's (1980) conceptualization of exchange resources, competence, skills, and efficiency seem more concrete, bordering on the goods and services classes rather than the status and information classes. This conceptualization therefore seems less relevant to the discretionary exchanges at the core of Blau's (1964) theorizing. Benevolence does seem to belong in the same class as the other justice dimensions, particularly interpersonal justice, but it encompasses a depth of relationship and loyalty that the justice forms do not (Mayer et al., 1995; Mayer \& Davis, 1999). Similarly, integrity encompasses concepts that lay outside of any of the four justice forms, including value congruence, discreetness, reliability, and promise fulfillment (Mayer et al., 1995; Mayer \& Davis, 1999). We therefore hypothesized:

Hypothesis 1. Procedural, distributive, interpersonal, and informational justice at time 1 are positively related to the willingness to be vulnerable form of trust at time 2.

Hypothesis 2. Ability, benevolence, and integrity at time 1 are positively related to the willingness to be vulnerable form of trust at time 2 .

\section{Predicting Justice: The Relational Model}

As noted above, many of the trustworthiness and justice dimensions are functionally similar and are likely to be highly related to one another. We now explore whether those relationships are causal. One theory that is relevant in this regard is the relational model (Tyler, 1994; Tyler \& Lind, 1992). Originally termed the "group-value model" (Lind \& Tyler, 1988; Tyler, 1989), this model arose as a means of explaining why voice improved reactions to decision events even when it did not result in more favorable outcomes. The basic assumption of the group-value model is that people value memberships in social groups because those groups provide a source of self-validation. The model further suggests that individuals look to three judgments as signals of how much their groups value them (Tyler, 1989: 831): (1) trust, which involves "the belief that the intentions of a third party are benevolent, that they desire to treat people in a fair and reasonable way"; (2) neutrality, which involves whether an authority in question "is an unbiased decision maker who is honest and who uses appropriate factual information to make decisions"; and (3) standing, which involves "polite and respectful treatment."

In his initial test, Tyler (1989) focused on citizens of Chicago. He suggested that the city itself might comprise a meaningful group and that citizens could look to their treatment by police or legal authorities as signals of how much the city valued them. Tyler measured reactions to decision events using several outcomes, including procedural and distributive justice. He also gathered data on outcome favorability by asking individuals whether actual decisions were in their favor. The study showed that all three group-value judgments were significant predictors of procedural and distributive justice, even when outcome favorability was controlled for. Thus, citizens did seem to look to trust, neutrality, and standing when deciding how to react to city authorities. At first glance, these results seem in direct opposition to Hypothesis 1, as they imply a trust to justice causal order. However, it must be noted that Tyler (1989) conceptualized trust as positive expectations about the benevolence and fairness of authority. In Mayer and colleagues' (1995) terms, that variable would be labeled a combination of benevolence and integrity. Thus, Tyler's (1989) study actually supports a trustworthiness to justice prediction.

The group-value model was subsequently relabeled the "relational model," with the three groupvalue judgments now grouped under the "relational judgments" heading (Tyler, 1994; Tyler \& 
Lind, 1992). One change that is particularly relevant to this discussion was a shift from the trust label to the trustworthiness label in descriptions of the relational judgments. Tyler (1994) conceptualized trustworthiness as positive perceptions about the motives of authority, which would fall under Mayer and colleagues' (1995) benevolence facet. Indeed, Tyler (1994) himself utilized the benevolence label in one passage referring to the trustworthiness variable and asked employees about their recent experiences with a supervisor in getting help on work-related problems, making resource allocation decisions, or settling disputes. As in the earlier study, Tyler (1994) measured reactions to decision events using several outcomes, including procedural and distributive justice, and also gathered data on outcome favorability. The results of the study again showed that trustworthiness, neutrality, and standing were significant predictors of procedural and distributive justice, even given controls for outcome favorability.

Taken together, these studies suggest that individuals look to three judgments-trustworthiness, neutrality, and standing-as signals of how much they are valued by their groups (Tyler, 1989, 1994). They consider those issues most intently when reacting to decision-making events and, as a result, those three judgments help shape justice perceptions. With respect to the role of trustworthiness specifically, the perception that authorities have benevolence and integrity is believed to create a lens through which people view subsequent decision-making actions over the long term (Tyler, 1989, 1994). That rationale is consistent with suggestions by trust scholars. For example, Robinson (1996) argued that believing authorities to be trustworthy creates selective perception, reducing the likelihood that the authorities' actions will be perceived as breaching agreed-upon codes of conduct. Similarly, Dirks and Ferrin (2001) noted that many of the actions observed in organizations are ambiguous to some degree, meaning that perceived trustworthiness can shape interpretations.

With regard to the time span involved in this relationship, it is important to note that many scholars believe that justice judgments take time to develop because they are based on an accumulation of experiences with a supervisor, such as resource allocations, dispute resolutions, or other similar events (Cropanzano et al., 2001). The reasoning that underlies the relational model suggests that evidence of trustworthiness-which also accumulates over repeated interactions with the supervisor (Mayer et al., 1995)—is one piece of information that employees collect during these experiences.
We therefore advanced the predictions below for the relationships among benevolence, integrity, and the justice dimensions. Note that we omitted ability from our hypotheses because tests of the relational model have focused more on the benevolence and integrity of authorities than on their competence (Lind, Tyler, \& Huo, 1997; Tyler, 1989, 1994; Tyler, Degoey, \& Smith, 1996). Note also that we included all four justice dimensions in our hypotheses. Although the relational model discusses reactions to decision events in relatively general terms, Tyler's $(1989,1994)$ tests of the model have included procedural and distributive justice, omitting the interactional justice facets. Two reasons could explain this omission. First, the justice literature as a whole has tended to lump procedural and interactional justice together. Second, elements of interpersonal justice are already represented in the standing portion of the model. Nevertheless, the core logic of the model would apply to interpersonal and informational reactions as well. We therefore predicted:

Hypothesis 3a. Benevolence at time 1 is positively related to procedural, distributive, interpersonal, and informational justice at time 2.

Hypothesis $3 b$. Integrity at time 1 is positively related to procedural, distributive, interpersonal, and informational justice at time 2.

\section{Predicting Trustworthiness: Fairness Heuristic Theory}

One other theory contains propositions relevant to the justice-trustworthiness connection. Fairness heuristic theory suggests that individuals in organizations face a "fundamental social dilemma" wherein cooperating with authorities can lead to better outcomes but can also increase the risk of exploitation (Lind, 2001; Van den Bos, 2001). According to the theory, in an effort to cope with this dilemma, individuals use a "fairness heuristic" as a shortcut to determine whether or not to cooperate. The theory details two general phases of working life: a relatively short "judgmental phase" and a longer "use phase." During the judgmental phase, individuals quickly arrive at a general justice judgment by assessing the available information. That information could be procedural, distributive, interpersonal, or informational in nature-the theory's argument is that the individuals will use whatever information is encountered first and is most interpretable to create the judgment. In the use phase, they assume this general heuristic to be accurate, and it impacts daily attitudes and behaviors (e.g., prosocial behavior, acceptance of authority). 
In talking about the importance of the fundamental social dilemma to the development of fairness heuristic theory, Van den Bos wrote, "These ideas led us to ask: Do people often have direct information about an authority's trustworthiness? We suggested that they frequently do not.... We suggested that in such situations-in which information about the authority's trustworthiness is missing-people refer to the fairness of the authority's procedures to decide how to react" (2001: 73). This logic seems to suggest that individuals will use data on justice as a signal when they form impressions of trustworthiness. However, the theory does not explicitly make that prediction, instead focusing on uncertainty about trustworthiness as a moderator of justice-outcome relationships. For example, in one experiment by Van den Bos, Wilke, and Lind (1998), participants were asked to imagine that they were applying for a grant, with the trustworthiness of the grant committee being manipulated to be high, low, or unknown. Procedural justice was shown to have stronger effects on satisfaction ratings when trustworthiness was unknown than when it was either high or low.

The Van den Bos and colleagues (1998: 1453) experiments manipulated trustworthiness information in a global fashion (i.e., by telling participants that the authority was "not to be trusted at all" or is "to be trusted completely"). Trustworthiness was not framed in more specific terms using information about ability, benevolence, or integrity. Moreover, the fact that justice and trustworthiness were manipulated so that they were orthogonal to one another prevented any sort of investigation of the justice-trustworthiness connection. However, discussions of fairness heuristic theory do make the case that justice perceptions can be formed more quickly and easily than trustworthiness judgments (Lind, 2001; Van den Bos, 2001). This is because justice can be gauged in terms of adherence to rules such as consistency, accuracy, correctability, respect, and justification-rules that are frequently encountered and often clear in their interpretation (Bies \& Moag, 1986; Leventhal, 1980). In contrast, Mayer and colleagues (1995) suggested that trustworthiness is often difficult to gauge, particularly in the case of benevolence. Such differences suggest that individuals will form justice perceptions before they form trustworthiness perceptions and be relatively more certain about the former, which comprise data for the assessment of trustworthiness. This line of reasoning further suggests that, if justice perceptions are to inform trustworthiness impressions, employees need sufficient opportu- nity to experience justice-laden events. We therefore predicted:

Hypothesis 4a. Procedural, distributive, interpersonal, and informational justice at time 1 are positively related to benevolence at time 2 .

Hypothesis 4b. Procedural, distributive, interpersonal, and informational justice at time 1 are positively related to integrity at time 2.

\section{METHODS}

\section{Participants}

Participants in this study were registered alumni from a large southeastern university. They were employed in a variety of different industries, the most common being retail, law, and hospitality. On average, participants were 44 years old (s.d. = 7.9 years), and 32 percent were female. Their average tenure with their current employer was 11.2 years (s.d. $=7.5$ years), a value that is consistent with those in past research integrating justice with trust. Of the 13 studies cited in Appen$\operatorname{dix}$ A, 5 had average respondent tenure levels of 10 years or more (Aryee et al., 2002; Kernan \& Hanges, 2002; Kim \& Mauborgne, 1993; Konovsky \& Pugh, 1994; Korsgaard, Sapienza, and Schweiger, 2002). That correspondence is helpful to support the notion that any differences between our results and extant research are a function of our decomposition of trustworthiness and trust and our use of longitudinal methods (as opposed to being a function of differences in tenure levels).

\section{Procedure}

The present study used a longitudinal design with two periods. George and Jones (2000) noted that most of the relationships studied in organizational behavior are not instantaneous, with changes in one construct instantly accompanied by changes in another. Instead, "some level of time aggregation is necessarily involved in most, if not all, theorizing" (George \& Jones, 2000: 670). As noted in the development of our hypotheses, the key question in testing our predictions concerns the time lag between the presence of causes and the demonstration of effects. Our goal was to select a time lag that was appropriate given the theoretical parameters reviewed in our introduction, which meant meeting four conditions: (1) that employees could have interactions with their supervisors that could supply relevant data on trustworthiness, (2) that employees could experience the sorts of decision events that can be used to gauge justice, (3) that 
employees could experience particular choices and contexts in which a willingness to be vulnerable to their supervisor could be considered, and (4) that employees would have enough time to engage in a controlled, cognitive translation of attitudes (e.g., justice, trustworthiness) into behavioral intentions (e.g., trust). We felt that these parameters pointed to a lag of months, as opposed to seconds, minutes, weeks, or years. Within that broad range, we specifically chose four months because it fulfilled the parameters above and fell within the boundaries used in prior multiwave studies of justice and trust, which have used lags from six weeks to ten months (e.g., Frazier, Johnson, Gavin, Gotty, \& Snow, 2010; Kernan \& Hanges, 2002).

Participants were recruited by mail through a letter describing the longitudinal nature of the study, which was described as focusing on "attitudes toward supervisors." This mailing also included a consent form and the first survey. Eight hundred thirty participants were sent the initial request letter and survey. One hundred sixty-nine of these requests were undeliverable, resulting in an initial pool of 661 individuals. Of these, 256 people completed the first survey, for a time 1 response rate of 39 percent. Four months after completing the first survey, participants were mailed the second survey. Two hundred nine individuals returned the second survey, resulting in a time 2 response rate of 82 percent. Two weeks after mailing each survey, we sent reminder postcards to participants who had not yet returned their completed survey. Of the final 209 participants, 7 had incomplete data and were removed from the study, resulting in a final sample of 202 participants (and an overall response rate of 31 percent). Data collection took place from January 2006 to January 2007, and individuals received a $\$ 17$ honorarium for their complete participation. Specifically, we attached $\$ 2$ to the first survey and provided the remainder of the payment as the surveys were completed and returned. Participants were also mailed reminder postcards to ensure the return of their completed surveys.

\section{Measures}

The study's framing and instructions utilized participants' immediate supervisors as the referents for their responses, rather than a more general authority such as top management or their overall organization. Although justice researchers have traditionally referenced procedural and distributive justice to organization and interpersonal and informational justice to supervisor, scholars now recognize that each of the justice dimensions can ema- nate from either organizational or supervisory sources (e.g., Blader \& Tyler, 2003; Rupp \& Cropanzano, 2002). From this perspective, adherence to justice rules can be a function of a supervisor's personal leadership style as much as of any formal system or set of policies. To guard against item priming or item context effects on the survey, we varied the order of the trustworthiness, justice, and trust scales (Podsakoff, MacKenzie, Lee, \& Podsakoff, 2003). Specifically, some versions of the survey began with the trustworthiness scales, others began with the justice scales, and still others began with the trust scale. The order of the remaining two sets of scales was then varied within each of those versions. All measures utilized previously published scales. Table 1 contains a complete list of items.

Trustworthiness. The trustworthiness facets were measured using scales designed by Mayer and Davis (1999) to assess the ability, benevolence, and integrity of a supervisor. Individuals used a scale ranging from 1, "strongly disagree," to 5, "strongly agree," to assess the extent to which they agreed with the statements in each scale. Given concerns about the inclusion of fairness content in trustworthiness and trust scales, we omitted two items when creating the integrity scale: "My supervisor has a strong sense of justice" and "My supervisor tries hard to be fair in dealing with others." It is important to note, however, that the tests of our hypotheses did not differ when our model testing included versus excluded these items. Coefficient alpha values for times 1 and 2, respectively, were: ability, .96 and .96; benevolence, .94 and .95; integrity, .87 and .85 .

Justice. We measured participant perceptions of procedural justice, distributive justice, interpersonal justice, and informational justice with the scale developed and validated by Colquitt (2001). Extent of agreement was assessed on a scale ranging from 1, "to a very small extent," to 5 , "to a very large extent." For procedural justice $(\alpha=.86$, time 1 , and .90, time 2), participants were told to "refer to the procedures your immediate supervisor uses to make decisions about pay, rewards, evaluations, promotions, assignments, etc." when assessing their agreement with each of seven items. These seven items assessed adherence to the rules outlined in Leventhal (1980) and Thibaut and Walker (1975). For distributive justice ( $\alpha=.97$, time 1 , and .98, time 2$)$, participants were instructed to "refer to the outcomes you receive from your job, such as pay, rewards, evaluations, promotions, assignments, etc." when assessing their agreement with four items. This four-item scale assessed adherence to 
TABLE 1

Factor Loadings and Equivalence in Measurement Model

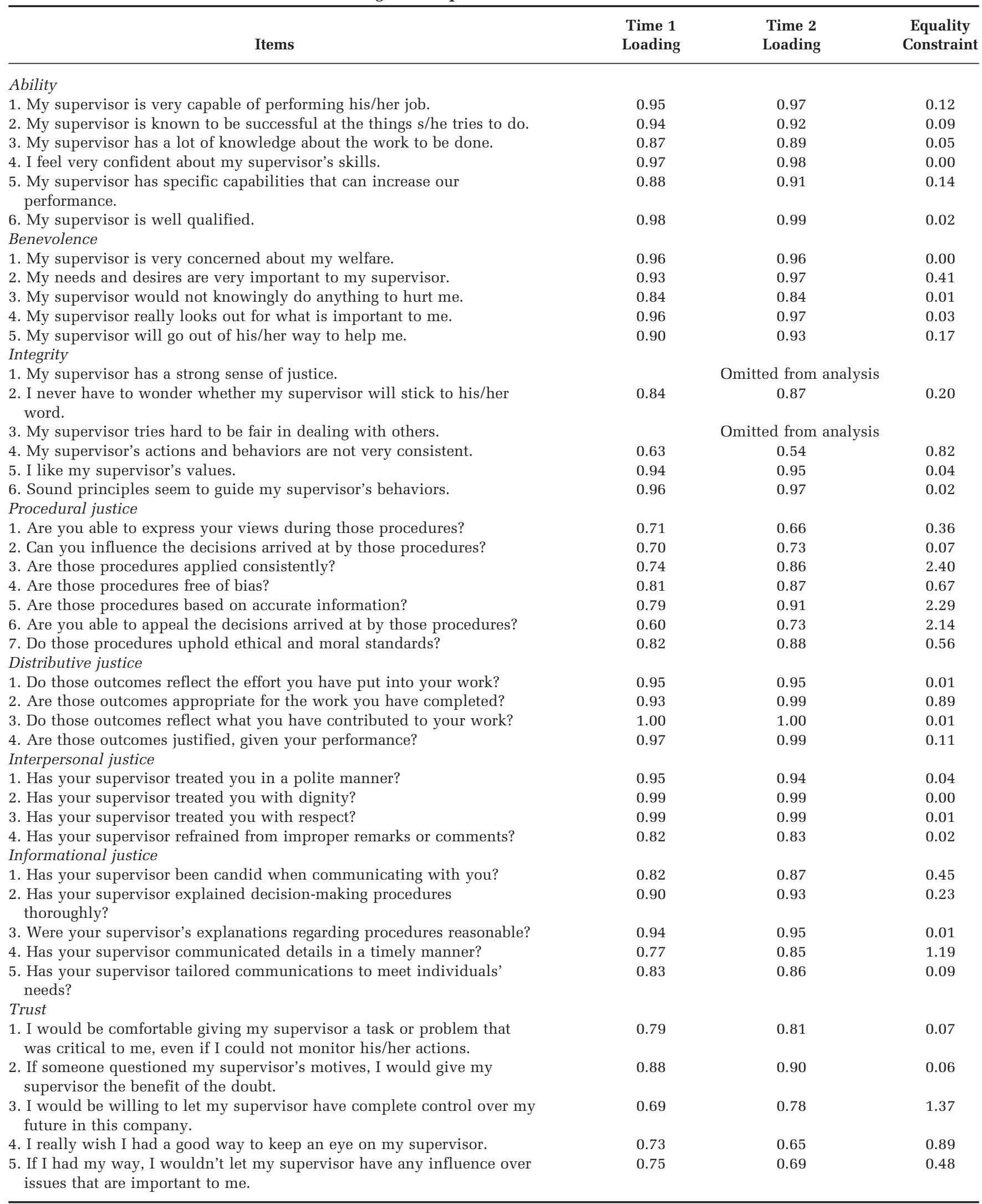


an equity rule (Adams, 1965; Leventhal, 1976). For interpersonal and informational justice, participants were simply asked to refer to "their immediate supervisor" when assessing agreement with the respective items. The items measuring interpersonal justice $(\alpha=.93$, time 1 , and .94 , time 2) referred to the interpersonal treatment participants received from their supervisors while procedures were enacted. These four items assessed adherence to the respect and propriety rules outlined in Bies and Moag (1986). For informational justice ( $\alpha=.90$, time 1 , and .93, time 2 ), participants were asked about their supervisors' communications and explanations for decision making. The five items assessed adherence to the justification and truthfulness rules outlined in Bies and Moag (1986).

Trust. We assessed trust with the five-item measure developed by Mayer and Gavin (2005), an update of Mayer and Davis's (1999) measure. Extent of agreement was assessed on scale ranging from 1, "strongly disagree," to 5, "strongly agree." These items were designed to capture participants' willingness to be vulnerable to their supervisor. The coefficient alpha for the trust scale was .82 at time 1 and .84 at time 2 .

\section{Data Analysis}

The first step in analyzing our data was examining the adequacy of our measurement model. As shown in Table 2, our hypothesized eight-factor model provided a good fit to the data at both time 1 $\left(\chi^{2}=1,163.16 ; \chi^{2} / d f=1.63 ;\right.$ CFI $=.99 ;$ IFI $=.99$; SRMR $=.047 ;$ RMSEA $=.050)$ and time 2 $\left(\chi^{2}=1,130.45 ; \chi^{2} / d f=1.55 ; \mathrm{CFI}=.99 ; \mathrm{IFI}=.99 ;\right.$ SRMR $=.041$; RMSEA $=.052)$. Good model fit is typically inferred when the $\chi^{2} / d f$ ratio falls below
3, when CFI and IFI rise above .90, and when SRMR and RMSEA fall near .05 (Kline, 2005). However, given the conceptual commonalities among many of our constructs, we investigated alternative measurement models. These included a model that combined all three trustworthiness facets into one factor, a model that combined trustworthiness and trust into one factor, a model that combined interpersonal and informational justice into an "interactional justice" factor, a model that combined all three forms of "process justice" into one factor, and a model that combined all four justice dimensions into a single "organizational justice" factor. All of these models resulted in a significant decrement in fit as judged by a chi-square difference test, so hypothesis testing proceeded with the eight-factor model. Table 1 provides the factor loadings for the eight scales. All factor loadings were statistically significant, with time 1 and time 2 averages as follows: ability (.93 and .94), benevolence (.92 and .93 ), integrity (.84 and .83), procedural justice (.74 and .80), distributive justice (.96 and .98), interpersonal justice (.94 and .94), informational justice (.85 and .89), and trust (.77 and .77).

Our hypotheses were tested using cross-lagged structural equation modeling. Farrell (1994) provided an extensive review of the steps involved in this approach to analyzing longitudinal data (see Epitropaki and Martin [2005] for one application in the organizational behavior literature). One of the first steps in the analysis is demonstrating equivalence in the measurement model across time periods. To test for equivalence, we introduced an equality constraint to the eight-factor model on an item-by-item basis. Table 1 provides the chi-square value for that constraint; values above 3.84 indicate that constraining the loadings to be equal resulted in a significant decrement in fit (Kline, 2005). None

TABLE 2

Comparison of Alternative Measurement Models

\begin{tabular}{|c|c|c|c|c|c|c|c|}
\hline Model & $\chi^{2}$ & $d f$ & $\chi^{2} / d f$ & CFI & IFI & SRMR & RMSEA \\
\hline \multicolumn{8}{|l|}{ Time 1} \\
\hline Eight-factor model & $1,163.16$ & 712 & 1.63 & .99 & .99 & .047 & $.050(.044, .056)$ \\
\hline Combined "trustworthiness" factor & $1,915.24$ & 725 & 2.64 & .97 & .97 & .062 & $.115(.110, .120)$ \\
\hline Combined "trustworthiness and trust" factor & $1,974.22$ & 730 & 2.70 & .97 & .97 & .063 & $.116(.111, .121)$ \\
\hline Combined “interactional justice” factor & $1,468.52$ & 719 & 2.04 & .98 & .98 & .061 & $.082(.077, .086)$ \\
\hline Combined "process justice" factor & $1,704.31$ & 725 & 2.35 & .98 & .98 & .061 & $.096(.091, .101)$ \\
\hline $\begin{array}{l}\text { Combined "organizational justice" factor } \\
\text { Time } 2\end{array}$ & $2,226.81$ & 730 & 3.05 & .96 & .96 & .071 & $.121(.117, .126)$ \\
\hline Eight-factor model & $1,103.45$ & 712 & 1.55 & .99 & .99 & .041 & $.052(.045, .058)$ \\
\hline Combined "trustworthiness" factor & $1,845.68$ & 725 & 2.55 & .98 & .98 & .056 & $.112(.107, .116)$ \\
\hline Combined "trustworthiness and trust" factor & $1,870.15$ & 730 & 2.56 & .98 & .98 & .056 & $.111(.106, .116)$ \\
\hline Combined "interactional justice" factor & $1,338.95$ & 719 & 1.86 & .99 & .99 & .045 & $.076(.071, .082)$ \\
\hline Combined "process justice" factor & $1,498.57$ & 725 & 2.07 & .98 & .98 & .048 & $.087(.082, .092)$ \\
\hline Combined "organizational justice" factor & $2,184.22$ & 730 & 2.99 & .97 & .97 & .060 & $.117(.113, .122)$ \\
\hline
\end{tabular}


of the chi-square values were significant, suggesting a fairly robust factor structure. Error covariances were then modeled between all of the time 1 and time 2 indicators, because repeated measures of the same variable often result in correlated errors.

Within the structural model, each time 2 variable was represented by its time 1 counterpart and the particular variables included in our hypotheses. We also modeled ability effects even when not hypothesized, to make our results as informative as possible. Following recommendations for crosslagged structural equation modeling, we modeled no cause-effect relationships between variables measured at the same time (Epitropaki \& Martin, 2005; Farrell, 1994). However, so-called synchronous correlations were modeled among the time 1 and time 2 variables to capture within-time covariation (Epitropaki \& Martin, 2005; Farrell, 1994). Time 1 synchronous correlations were modeled by allowing the exogenous latent variables to covary, and time 2 synchronous correlations were modeled by allowing the disturbance terms for the endogenous latent variables to covary. The combination of all of these paths resulted in a good fit to the data $\left(\chi^{2}=3,986.13 ; \chi^{2} / d f=1.35 ; \mathrm{CFI}=.99 ; \mathrm{IFI}=.99 ;\right.$ SRMR $=.050 ;$ RMSEA $=.042$ ).

\section{RESULTS}

Table 3 shows the means, standard deviations, and zero-order correlations among the time 1 and time 2 variables. Table 4 summarizes the structural path coefficients used to test our hypotheses. Fig- ures 3A-3C provide visual representations of those analyses, with trust, justice, and trustworthiness as the respective outcomes. It is important to note that it is these three figures, in combination, that represent the structural model being tested. In the interest of clarity, the figures omit factor loadings, error covariances between time 1 and time 2 indicators, covariances among latent exogenous variables, covariances among time 2 disturbance terms, and nonsignificant paths.

Hypothesis 1 predicts that procedural, distributive, interpersonal, and informational justice measured at time 1 will be positively related to trust measured at time 2. Hypothesis 2 predicts that ability, benevolence, and integrity measured at time 1 will be positively related to trust measured at time 2 . The portion of our structural model relevant to these hypotheses regressed time 2 trust onto its time 1 counterpart, along with the time 1 justice and trustworthiness dimensions. As shown in Table 4 and Figure 3A, both hypotheses were partially supported. When the analysis controlled for trust's stability coefficient $(\beta=.35)$, informational justice $(\beta=.18)$, benevolence $(\beta=.19)$, and integrity $(\beta=.21)$ had significant unique relationships with trust at time 2. These results support the notion that justice leads to trust, even when both trustworthiness and prior trust levels are controlled for. They also suggest that informational justice has special relevance to the willingness to be vulnerable.

Hypothesis 3 predicts that benevolence and integrity assessed at time 1 will be positively re-

TABLE 3

Means, Standard Deviations, and Zero-Order Correlations ${ }^{\text {a }}$

\begin{tabular}{|c|c|c|c|c|c|c|c|c|c|c|c|c|c|c|c|c|c|}
\hline Variable & Mean & s.d. & 1 & 2 & 3 & 4 & 5 & 6 & 7 & 8 & 9 & 10 & 11 & 12 & 13 & 14 & 15 \\
\hline \multicolumn{18}{|l|}{ Time 1} \\
\hline 1. Ability & 4.12 & 0.88 & & & & & & & & & & & & & & & \\
\hline 3. Integrity & 3.77 & 0.89 & .66 & .78 & & & & & & & & & & & & & \\
\hline 4. Procedural justice & 3.47 & 0.76 & .49 & .59 & .58 & & & & & & & & & & & & \\
\hline 5. Distributive justice & 3.56 & 1.08 & .43 & .53 & .46 & .61 & & & & & & & & & & & \\
\hline 8. Trust & 3.70 & 0.84 & .70 & .70 & .73 & .65 & .43 & .57 & .69 & & & & & & & & \\
\hline \multicolumn{18}{|l|}{ Time 2} \\
\hline 9. Ability & 4.12 & 0.84 & .75 & .57 & .59 & .46 & .46 & .52 & .61 & .64 & & & & & & & \\
\hline 10. Benevolence & 3.70 & 0.92 & .53 & .77 & .69 & .56 & .54 & .64 & .66 & .64 & .68 & & & & & & \\
\hline 11. Integrity & 3.74 & 0.86 & .55 & .65 & .74 & .52 & .45 & .59 & .63 & .67 & .70 & .81 & & & & & \\
\hline 12. Procedural justice & 3.46 & 0.80 & .44 & .58 & .60 & .70 & .53 & .51 & .58 & .56 & .57 & .75 & .72 & & & & \\
\hline
\end{tabular}

${ }^{\mathrm{a}} n=202$. All correlations are significant at $p<.01$. 
TABLE 4

Results of Structural Equation Modeling ${ }^{\text {a }}$

\begin{tabular}{|c|c|c|c|c|c|c|c|c|}
\hline Time 1 Predictors & \multicolumn{8}{|c|}{ Time 2 Outcomes } \\
\hline Ability & $.66^{*}$ & - & - & -.06 & $-.15^{*}$ & .00 & -.03 & -.09 \\
\hline Benevolence & - & $.66^{*}$ & - & .09 & -.07 & -.05 & .13 & $.19^{*}$ \\
\hline Integrity & - & - & $.48^{*}$ & $.25^{*}$ & $.30^{*}$ & $.25^{*}$ & $.23^{*}$ & $.21^{*}$ \\
\hline Interpersonal justice & .10 & $.12^{*}$ & $.14^{*}$ & - & - & $.66^{*}$ & - & -.05 \\
\hline Informational justice & .14 & -.04 & .13 & - & - & - & $.48^{*}$ & $.18^{*}$ \\
\hline Trust & - & - & - & - & - & - & - & $.35^{*}$ \\
\hline
\end{tabular}

${ }^{a}$ Contents are standardized path coefficients. Dashes (-) represent paths fixed to zero within the structural equation model. ${ }^{*} p<.05$, one-tailed.

lated to procedural, distributive, interpersonal, and informational justice at time 2 . The portion of our structural model relevant to these hypotheses regressed the time 2 justice dimensions onto their time 1 counterparts, along with the time 1 trustworthiness dimensions. As shown in Table 4 and Figure 3B, the hypothesis was partially supported. When we controlled for their stability coefficients (which ranged from .48 to .66), integrity had significant, unique relationships with procedural justice $(\beta=.25)$, distributive justice $(\beta=.30)$, interpersonal justice $(\beta=.25)$, and informational justice $(\beta=.23)$. These results support the notion that the integrity dimension of trustworthiness leads to justice, though the benevolence dimension does not. Effects for ability were modeled on an exploratory basis; ability had a significant, negative relationship with distributive justice $(\beta=-.15)$.

Hypothesis 4 predicts that procedural, distributive, interpersonal, and informational justice measured at time 1 will be positively related to benevolence and integrity at time 2 . The portion of our structural model relevant to these hypotheses regressed the time 2 trustworthiness dimensions onto their time 1 counterparts, along with the time 1 justice dimensions. As shown in Figure 3C, the hypothesis was partially supported. Interpersonal justice $(\beta=.12)$ had a significant, unique relationship with benevolence when the analysis controlled for the benevolence stability coefficient $(\beta=.66)$. Procedural justice $(\beta=.15)$ and interpersonal justice $(\beta=.14)$ had significant, unique relationships with integrity when the analysis controlled for the integrity stability coefficient $(\beta=.48)$. Effects for ability were modeled and were nonsignificant, as expected.

\section{DISCUSSION}

In the present study, we attempted to move beyond the conventional wisdom that justice leads to trust by bringing more nuanced theorizing and more rigorous methods to the study of this important connection. Utilizing Mayer and colleagues' (1995) distinction between trustworthiness and trust allowed us to look separately at the relationship between justice and the willingness to be vulnerable and the relationship between justice and trustworthiness. As a result, several key findings emerged. First, with regard to the relationship between justice and trust, informational justice appears to hold a unique relevance to the willingness to be vulnerable. Of the four justice dimensions, it was the only one that predicted trust when trustworthiness was considered simultaneously. Second, with regard to the relationship between justice and trustworthiness, there appears to be a reciprocal relationship between justice and benevolence and integrity. Managers who adhered to procedural and interpersonal justice rules were perceived to be more trustworthy, and vice versa. Third, the connection between trustworthiness and justice is weaker when trustworthiness is operationalized in ability terms. The competence, skills, and efficiency of a manager appear to have little bearing on whether that manager adheres to justice rules.

\section{Justice and Trust: Informational Justice Stands Out}

One of the central theoretical questions examined in our study concerns whether justice really does lead to trust, as the conventional wisdom depicted in Figure 1 suggests. More specifically, when trust is expressed as the willingness to be 


\section{FIGURE 3A}

Portion of Structural Model Relevant to Hypotheses 1-2

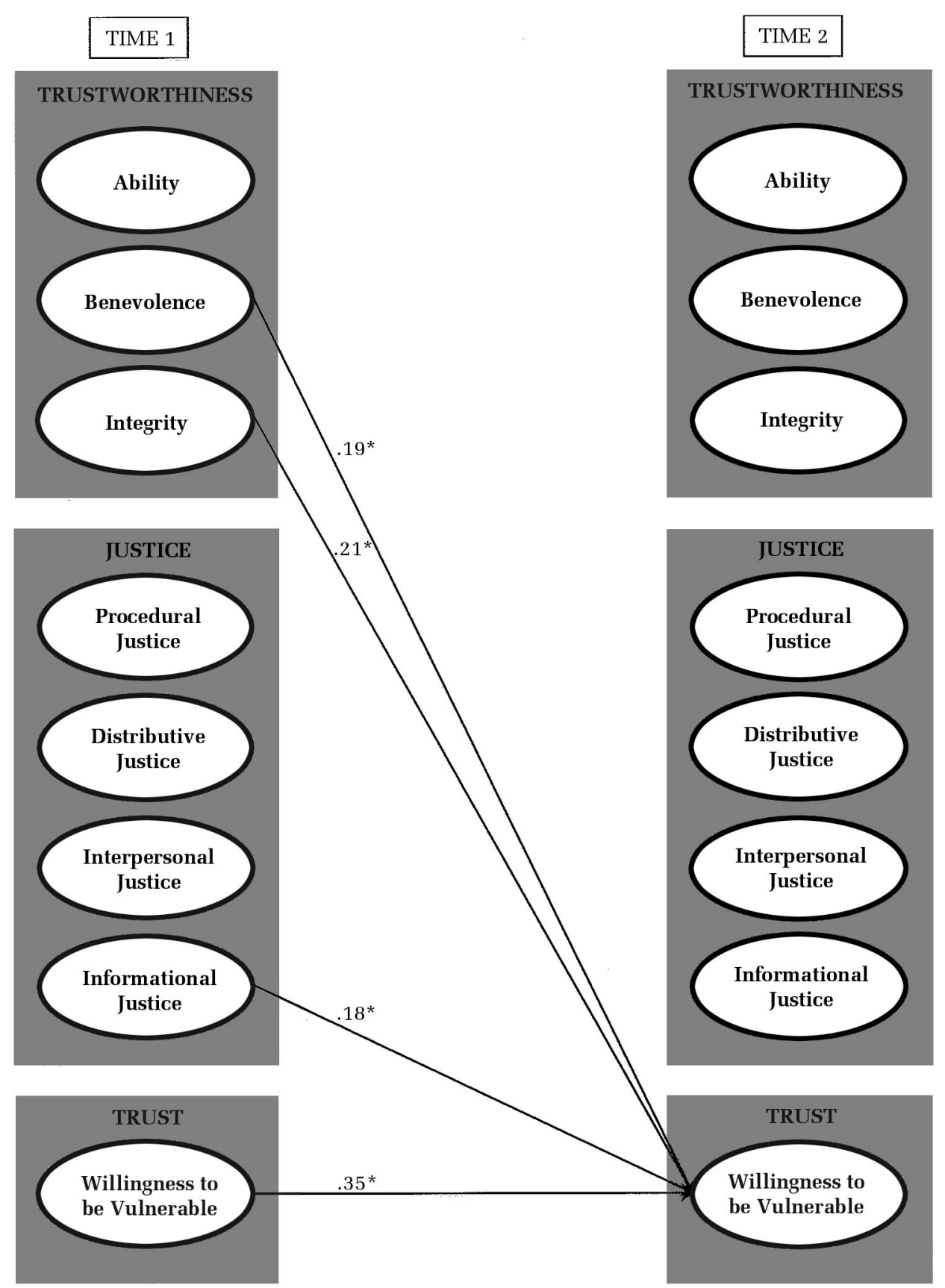

a The structural model tested represents a combination of Figures 3A, 3B, and 3C. Path coefficients are standardized. The following paths are omitted for the purposes of clarity: factor loadings, error covariances between time 1 and time 2 indicators, covariances among exogenous latent variables, covariances among time 2 disturbance terms, and nonsignificant paths.

vulnerable, with justice concepts and trustworthiness concepts removed from its operationalization, does the relationship with justice still hold? The notion that fair decision making fosters a willingness to accept vulnerability has been a cornerstone of the application of social exchange theory in the justice literature (Konovsky \& Pugh, 1994; Organ,
1990). Social exchanges cannot develop without a willingness to trust that an exchange partner will eventually discharge his or her obligations (Blau, 1964), and justice could provide a signal that fair principles will govern exchanges with that partner (Brockner \& Siegel, 1995; Konovsky \& Pugh, 1994; Organ, 1990). Our results showed that informa- 
FIGURE 3B

Portion of Structural Model Relevant to Hypothesis $3^{\text {a }}$

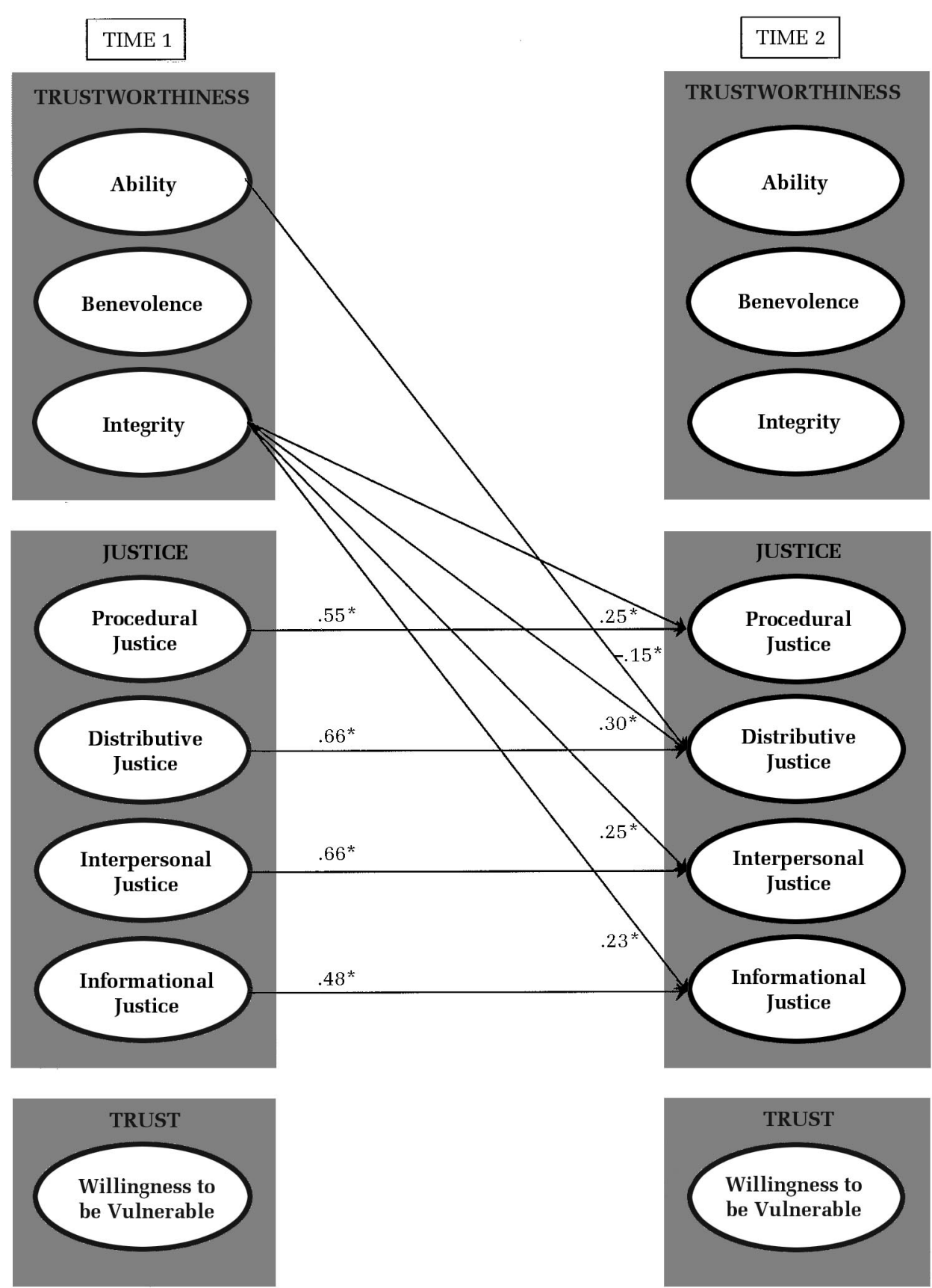

a The structural model tested represents a combination of Figures 3A, 3B, and 3C. Path coefficients are standardized. The following paths are omitted for the purposes of clarity: factor loadings, error covariances between time 1 and time 2 indicators, covariances among exogenous latent variables, covariances among time 2 disturbance terms, and nonsignificant paths.

tional justice was the only justice dimension to predict the willingness to be vulnerable: employees were more trusting of supervisors who explained and justified decision making in an honest and truthful manner. That informational effect was significant even when we controlled for prior levels of the willingness to be vulnerable and for prior perceptions of trustworthiness.

Why does informational justice seem to hold a unique relevance to the willingness to be vulnerable, particularly when meta-analyses have also supported the importance of the procedural and dis- 
FIGURE 3C

\section{Portion of Structural Model Relevant to Hypothesis $4^{\mathrm{a}}$}
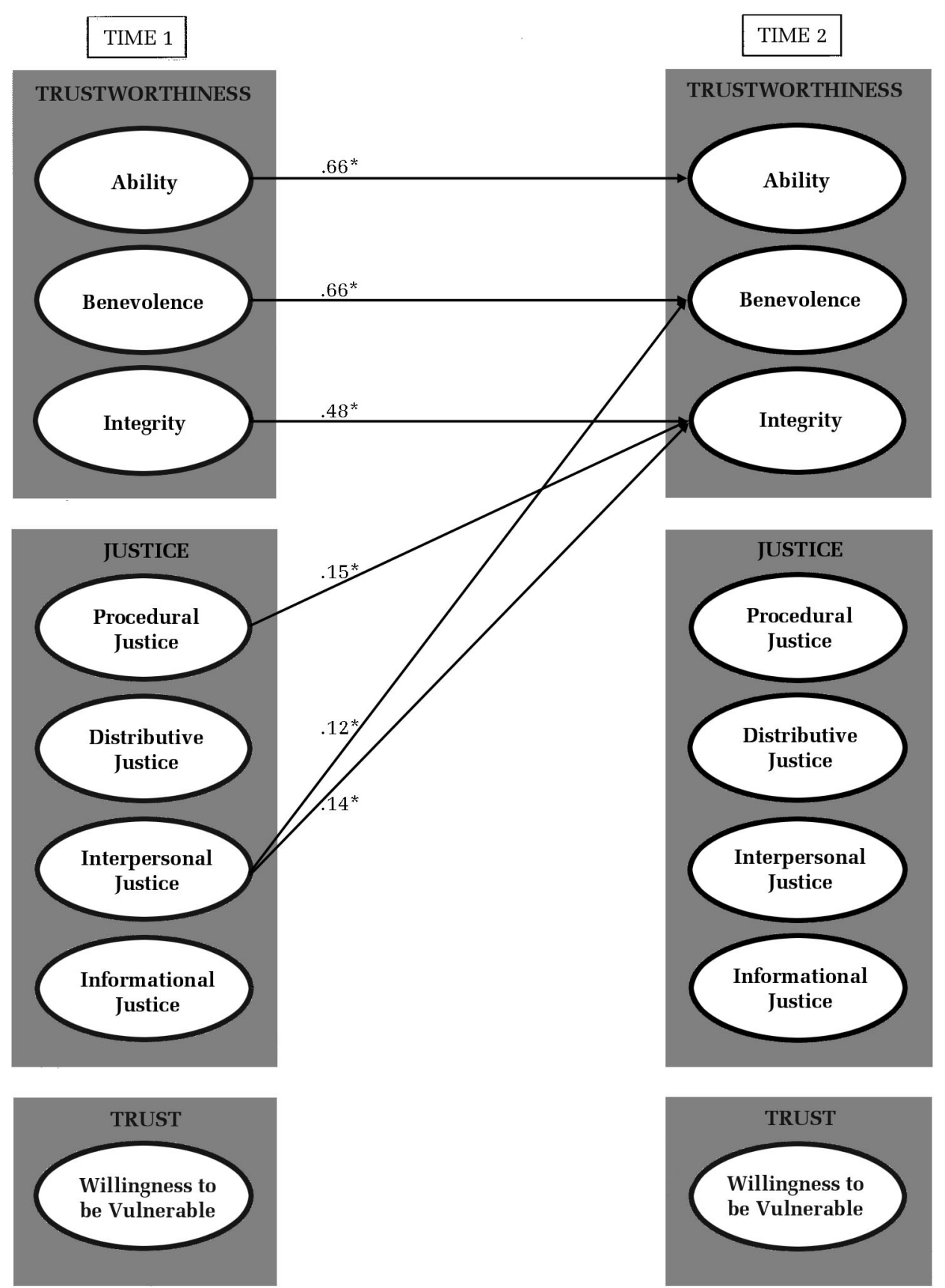

${ }^{a}$ The structural model tested represents a combination of Figures 3A, 3B, and 3C. Path coefficients are standardized. The following paths are omitted for the purposes of clarity: factor loadings, error covariances between time 1 and time 2 indicators, covariances among exogenous latent variables, covariances among time 2 disturbance terms, and non-significant paths.

tributive facets to other kinds of trust measures (Cohen-Charash \& Spector, 2001; Colquitt et al., 2001; Dirks \& Ferrin, 2002)? Two issues may offer answers to that question. First, it may be that past research has overstated the importance of the other justice facets by including justice concepts in trust measures. Second, it may be that the other justice dimensions are more functionally similar to benevolence and integrity-inspiring a willingness to be vulnerable for the very same reasons as those trustworthiness dimensions. To borrow a distinction from McAllister's (1995) work, it may be that informational justice captures affect-based reasons to trust, in addition to the more cognition-based rea- 
sons reflected by trustworthiness. McAllister (1995) described affect-based trust as trust based on emotional investments and ties. In large part, his measure of affect-based trust focuses on the mutual sharing of ideas and feelings and the sense that individuals can talk freely to one another. In the validation of his justice measure, Colquitt (2001) suggested that informational justice conveys a sense of inclusion, with being "in the know" signaling being "in the in-group." Thus, managers who share honest and truthful justifications for key events may foster emotional ties with subordinates-ties that create their own unique reasons for a willingness to be vulnerable.

These results have important theoretical implications for social exchange theory, particularly as it is applied in the justice literature. Applications of the theory have tended to stress procedural justice as the exchange currency capable of breeding reciprocation in the form of citizenship and related behaviors (Konovsky \& Pugh, 1994; Organ, 1990). It may be that informational justice is the more critical exchange currency. After all, of the four justice dimensions, informational justice best captures the information and status resources described in Foa and Foa's (1980) conceptualization of exchange theory. Because such resources are highly particularistic and symbolic, they may be uniquely capable of fostering the trust levels needed to breed a social exchange.

\section{Trustworthiness and Justice: A Reciprocal Relationship with Benevolence and Integrity}

Applying the Mayer and colleagues (1995) lens rather than the confident, positive expectations view of trust allowed us to examine, for the first time, the relationships among the justice dimensions and the ability, benevolence, and integrity of supervisors. For benevolence and integrity, our results suggest that the relationship between those trustworthiness forms and justice is reciprocal, with both influencing one another, as shown in Figure 2. On the one hand, our results suggest that integrity predicts subsequent perceptions of all four justice dimensions, even when their prior levels are controlled for. Managers who stuck to their word and whose actions were guided by sound values and principles were perceived to be fairer. On the other hand, justice perceptions also predicted subsequent perceptions of benevolence and integrity, even when prior assessments were controlled for. Interpersonal justice had a positive effect on perceived benevolence, suggesting that adhering to rules such as respect and propriety signaled that authorities were concerned about the welfare of employees. Procedural and interpersonal justice had positive effects on perceived integrity, suggesting that adherence to those rules signaled that authorities used sound values and principles to guide their actions.

Taken together, these results have important theoretical implications for the relational model and for fairness heuristic theory. With respect to the former, the relational model suggests that some combination of benevolence and integritywhether labeled "benevolence," "trustworthiness," or merely "trust" in formal specifications of the model-acts as an antecedent of justice perceptions (Tyler, 1989, 1994; Tyler \& Lind, 1992). Our results suggest that this causal flow is an oversimplification, in that justice guides views on trustworthiness as much as trustworthiness guides views on justice. With respect to the latter, fairness heuristic theory implies that justice perceptions guide formation of trustworthiness perceptions, because information on justice is encountered earlier (and is more interpretable) than information on trustworthiness (Lind, 2001; Van den Bos, 2001; Van den Bos et al., 1998). Once again, that causal flow seems to be an oversimplification. It may be that the perception that an authority has integrity creates a sort of selective perception through which people view justice-relevant actions (Dirks \& Ferrin, 2001; Robinson, 1996; Tyler, 1989, 1994).

In our opinion, future work in this area would benefit from a theoretical compromise between the relational model and fairness heuristic theory, one acknowledging a sound conceptual logic for a trustworthiness to justice causal order and a justice to trustworthiness causal order. That sort of compromise would offer important new insights for the modeling of justice and trustworthiness in future studies. Specifically, it would suggest that scholars should either model nonrecursive paths between justice and trustworthiness, or simply model them as correlates that occupy the same functional position in a causal system. If they are exogenous in a causal system, such as in cases in which they predict reciprocative attitudes or behaviors, they would be connected by a modeled covariance (i.e., a curved arrow). If they are endogenous in a causal system, such as in cases in which they mediate organizational or supervisory effects, they would either be connected by nonrecursive paths or by a disturbance covariance (neither of which affords causal primacy). This compromise matches Lewicki and colleagues' (2005) suggestion that justice and trustworthiness can be described as correlates that "codevelop."

An alternative possibility is that justice and trustworthiness do not codevelop, but rather that justice 
is a component of trustworthiness. This possibility seems most applicable to the relationship between justice and integrity, given that Mayer and Davis's (1999) integrity scale includes two items that use the words "justice" or "fairness." We believe that at least two conceptual reasons exist for maintaining the separation of justice and integrity as constructs. First, Mayer et al. (1995) described integrity as an "attribute" or "characteristic" of a trustee. Integrity is something that a person has-just as "trustworthy" is something that a person is. In other words, integrity is a personal quality that exists across situations. In contrast, justice reflects something that a person does-more specifically, a set of rules that a person adheres to in the context of decisionmaking and resource allocation events. Second, Mayer and colleagues' (1995) conceptualization of integrity includes a number of concepts that do not overlap substantially with the rules represented by procedural, distributive, interpersonal, or informational justice. Those concepts include value congruence, discreetness, reliability, and promise fulfillment. Similarly, the rules used to operationalize justice include a number of concepts that do not overlap substantially with integrity. Those concepts include voice, input, accuracy, correctability, equity, and justification (Adams, 1965; Bies \& Moag, 1986; Leventhal, 1980; Thibaut \& Walker, 1975).

Of course, even if justice and integrity can be separated conceptually, the question of how to handle the inclusion of fairness content in Mayer and Davis's (1999) scale remains. In a general sense, measures are created to serve as content-valid operationalizations of the constructs within a given literature (Schwab, 1980; Stone-Romero, 1994). Aside from working to establish discriminant or predictive validity, researchers have paid relatively little attention to construct definitions or scale items in other literatures. This somewhat insular focus does not become problematic until a given literature becomes integrated with another with similar construct content. For example, Mowday, Steers, and Porter (1979) defined organizational commitment as the strength of an individual's identification with and involvement in an organization, characterizing involvement as a willingness to exert extra effort on behalf of his/her organization. Mowday and colleagues' (1979) organizational commitment measure included indicators of involvement such as "I am willing to put in a great deal of effort beyond what is expected" and "I talk up this organization to my friends." Although that construct definition and item content functioned effectively in the organizational commitment literature, it became problematic when the construct was integrated with research on organizational citizenship behavior, which is defined as employees' discretionary effort that benefits their organization (Organ, 1990), and is measured with items very similar to the Mowday and colleagues' (1979) examples (e.g., Lee \& Allen, 2002).

In the same way that the definitions and scales used for organizational commitment and organizational citizenship behavior evolved over time to minimize the area of overlap, it may be that the definitions and scales used for justice and integrity need to evolve as well. That evolution could occur through an emphasis on the construct content that does not overlap between the two constructs, accompanied by new scales being validated to focus on that nonoverlapping content. Alternatively, that evolution could occur by scholars' ceding conceptual space to one construct or the other on the basis of how central the content is to the constructs. For example, it may be that "fairness" is more central to justice, meaning that it would be included in a justice scale but not an integrity scale, but that "ethicality" is more central to integrity, meaning that it would be included in an integrity scale but not a justice scale. Of course, that sort of integrative construct validation work has to occur for scholars to begin using such scales. Until those debates and validation efforts have been completed, the best solution likely remains the omission of items with overlapping content from scales such as Colquitt's (2001) or Mayer and Davis's (1999), as long as the adapted measure continues to tap the core of the relevant construct.

\section{Trustworthiness and Justice: Less Importance for Ability}

Although our results support a nonrecursive relationship between justice and both benevolence and integrity, the same cannot be said for ability. Ability was not a significant predictor of subsequent justice levels, nor were the justice dimensions shown to be predictors of subsequent ability. The one exception concerned distributive justice, as managers who were perceived as more competent and efficient were viewed as less equitable in their outcome allocations. That result is surprising, as one would expect high levels of ability to translate into a more accurate perception of employee inputs.

We can envision three potential reasons for a negative relationship between ability and distributive justice. First, it may be that more able managers create more outcome differentiation in their units, because they have a clearer sense of the relevant "compensable factors" that are used in 
formal and informal job evaluation efforts (Milkovich \& Newman, 2002). Although that increased differentiation may seem equitable to able managers, self-serving biases may create perceptions of inequity among the rank and file. Second, it may be that equity expectations are simply higher for more able managers, with employees "raising the bar" for what constitutes a balanced outcomeinput ratio. Third, it may be that able managers earn particularly high salaries precisely because of their high competence. Research suggests that employees may use upward comparisons when considering equity levels (Scholl, Cooper, \& McKenna, 1987), raising the possibility that they will view their managers' salaries as too high, even given their ability levels.

Aside from that result, however, the relationship between trustworthiness and justice was due primarily to benevolence and integrity. The relative importance of those facets flows out of both the relational model and fairness heuristic theory, as neither theory discusses the ability component of trustworthiness to a significant degree. It should be noted, however, that many of the trust measures in our appendix included ability concepts, likely driving down relationships with justice. Our results therefore offer another benefit of applying the more specific Mayer and colleagues (1995) lens to the study of justice, trust, and trustworthiness.

\section{Limitations and Suggestions for Future Research}

This study has several limitations that should be noted. First, although we used a longitudinal design in which prior levels of the key variables were controlled, our data are still ultimately correlational. The only way to draw definitive causal conclusions is to utilize experimental methods in which random assignment can be used to eliminate alternative explanations. Second, our study was conducted using veteran employees, not organizational newcomers. Although this sample made our study consistent with those cited in Appendix A, it should be noted that fairness heuristic theory's propositions are centered on newcomers. Third, all of our measures are taken from a common source, raising the possibility of correlation inflation due to common method variance. Once again, however, this feature makes our study more comparable to virtually all of the studies on justice and trust, as that linkage is commonly examined using samesource data. Our longitudinal design did allow us to separate measurements in time, removing transient sources of method variance such as "state affect" (Podsakoff et al., 2003). Fourth, as with many studies in organizational behavior, our theorizing addressed the role of time in the relationship between the constructs on a fairly imprecise basis. Thus, we reiterate the call of George and Jones (2000) to explicitly address time in one's theorizing, given that a number of different lags may be more appropriate for relationships among justice, trustworthiness, and trust.

One last limitation points to an important avenue for future research. Specifically, we neglected to include job performance in our study, an omission preventing us from assessing the relative performance effects of trustworthiness, justice, and trust. We decided to omit performance because the focus of our study was on bringing more nuance to the justice-trust connection, and because justice, trust, and performance variables have been included in four separate meta-analyses (Cohen-Charash \& Spector, 2001; Colquitt et al., 2001, 2007; Dirks \& Ferrin, 2002), two of which coded the variables at the level of specificity utilized in our study (Colquitt et al., 2001, 2007). Those results suggest that all three trustworthiness dimensions, two of the four justice dimensions, and the willingness to be vulnerable have significant relationships with job performance. The willingness to be vulnerable effect tends to be stronger than the others, which is consistent with the view that trust lies "downstream" from trustworthiness and justice, making it a more proximal predictor of performance. Still, few of the studies included in those meta-analytic reviews looked at relationships over time, and virtually none utilized the sort of panel data used in our study. We therefore recommend that scholars collect performance data alongside justice and trust data over time, to continue to tease out the performance implications of these concepts.

As a second suggestion for future research, we would call for more research integrating justice and trust using a Mayer and colleagues (1995) lens. This study is insufficient for balancing the 13 studies included in our appendix that use a confident, positive expectations framework, not to mention the other studies that use ad hoc or direct measures of trust. For conducting such research, we would offer the following suggestions to maximize internal and external validity. With respect to internal validity, we continue to suggest that scholars trim any items that could create overlapping content correlations, at least until new scales are validated, so long as doing so does not hinder content validity to an unacceptable degree. In addition, laboratory studies could be used to examine the potentially reciprocal relationship between justice and trustworthiness. Doing this would involve manipulating information about justice and measuring per- 
ceptions of trustworthiness, and manipulating information about trustworthiness and measuring perceptions of justice. The laboratory could also provide a useful venue for examining the cognitive mechanisms that underlie such justice-trustworthiness relationships. With respect to external validity, it would be beneficial to explore other relationship referents in work integrating justice and trust. Meta-analytic reviews have suggested that many trust and trustworthiness relationships are robust to use of different kinds of trust referents (Colquitt et al., 2007; Dirks \& Ferrin, 2002). Future work should explore whether the relationships observed here generalize when "top management" or "the overall organization" is used as the referent for the justice, trust, and trustworthiness measures.

\section{Practical Implications}

Our results have important practical implications for managers. For example, they show that offering honest justifications and explanations continues to matter even after participants have formed impressions about their trust in their supervisor and their perception of the supervisor's trustworthiness. Fortunately for managers, studies have shown that supervisors can be trained to adhere to justice principles (Skarlicki \& Latham, 2005). We suspect that many organizations view such training programs as relevant only to new supervisors, so that those supervisors can "get off on the right foot." The fact that informational justice continues to matter shows that such training could benefit established supervisors as well. Our results for benevolence and integrity also have important practical implications. Being concerned about the welfare of employees, sticking to one's word, and using sound values and principles to guide actions predicted subsequent trust levels even after trust and justice perceptions had been formed. It seems likely that supervisors would benefit from the incorporation of benevolence and integrity content into the development and assessment efforts in which they participate. More frequent feedback from employees on managers' benevolence and integrity could help managers nurture and maintain their levels of perceived trustworthiness.

\section{Conclusions}

For all the theoretical and empirical work integrating justice and trust, the connection between the two remains poorly understood (Lewicki et al., 2005). Indeed, the literature seems to be marked by the deceptively uncontroversial no- tion that justice leads to trust (Cohen-Charash \& Spector, 2001; Colquitt et al., 2001; Dirks \& Ferrin, 2002). We argued that this conventional wisdom is the result of coarse theorizing that has hindered the accumulation of valid knowledge about the justice-trust connection. Mayer and colleagues' (1995) model is capable of bringing more nuance and operational precision to this area of inquiry. Our hope is that future research will continue to assess trustworthiness, justice, and trust in combination when testing and applying social exchange theory, the relational model, and fairness heuristic theory. Only then can research yield valid prescriptions for how managers can best foster a willingness to be vulnerable on the part of their employees.

\section{REFERENCES}

Adams, J. S. 1965. Inequity in social exchange. In L. Berkowitz (Ed.), Advances in experimental social psychology, vol. 2: 267-299. New York: Academic Press.

Ambrose, M. L., \& Schminke, M. 2003. Organization structure as a moderator of the relationship between procedural justice, interactional justice, perceived organizational support, and supervisory trust. Journal of Applied Psychology, 88: 295-305.

Aryee, S., Budhwar, P. S., \& Chen, Z. X. 2002. Trust as a mediator of the relationship between organizational justice and work outcomes: Test of a social exchange model. Journal of Organizational Behavior, 23: 267-285.

Azjen, I. 1991. The theory of planned behavior. Organizational Behavior and Human Decision Processes, 50: 179-211.

Azjen, I., \& Fishbein, M. 1980. Understanding attitudes and predicting social behavior. Englewood Cliffs, NJ: Prentice-Hall.

Begley, T. M., Lee, C., \& Hui, C. 2006. Organizational leadership as a moderator of the relationship between justice perceptions and work-related reactions. Journal of Organizational Behavior, 27: 705721.

Bies, R. J., \& Moag, J. F. 1986. Interactional justice: Communication criteria of fairness. In R. J. Lewicki, B. H. Sheppard \& M. H. Bazerman (Eds.), Research on negotiations in organizations, vol. 1: 43-55. Greenwich, CT: JAI.

Blader, S. L., \& Tyler, T. R. 2003. What constitutes fairness in work settings? A four-component model of procedural justice. Human Resource Management Review, 13: 107-126.

Blau, P. M. 1964. Exchange and power in social life. New York: Wiley. 
Brockner, J., \& Siegel, P. 1995. Understanding the interaction between procedural and distributive justice: The role of trust. In R. M. Kramer \& T. R. Tyler (Eds.), Trust in organizations: Frontiers of theory and research: 390-413. Thousand Oaks, CA: Sage.

Cohen-Charash, Y., \& Spector, P. E. 2001. The role of justice in organizations: A meta-analysis. Organizational Behavior and Human Decision Processes, 86: $278-321$.

Colquitt, J. A. 2001. On the dimensionality of organizational justice: A construct validation of a measure. Journal of Applied Psychology, 86: 386-400.

Colquitt, J. A., Conlon, D. E., Wesson, M. J., Porter, C. O. L. H., \& Ng, K. Y. 2001. Justice at the millennium: A meta-analytic review of 25 years of organizational justice research. Journal of Applied Psychology, 86: 425-445.

Colquitt, J. A., Scott, B. A., \& LePine, J. A. 2007. Trust, trustworthiness, and trust propensity: A meta-analytic test of their unique relationships with risk taking and job performance. Journal of Applied Psychology, 92: 909-927.

Cook, J., \& Wall, T. D. 1980. New work attitude measures of trust, organizational commitment, and personal need non-fulfillment. Journal of Occupational Psychology, 53: 39-52.

Cropanzano, R., Byrne, Z. S., Bobocel, D. R., \& Rupp, D. E. 2001. Moral virtues, fairness heuristics, social entities, and other denizens of organizational justice. Journal of Vocational Behavior, 58: 164209.

Cropanzano, R., \& Mitchell, M. S. 2005. Social exchange theory: An interdisciplinary review. Journal of Management, 31: 874-900.

Cropanzano, R., Prehar, C., \& Chen, P. Y. 2002. Using social exchange theory to distinguish procedural from interactional justice. Group and Organization Management, 27: 324-351.

Dirks, K. T., \& Ferrin, D. L. 2001. The role of trust in organizational settings. Organization Science, 12: $450-467$.

Dirks, K. T., \& Ferrin, D. L. 2002. Trust in leadership: Meta-analytic findings and implications for research and practice. Journal of Applied Psychology, 87: 611-628.

Epitropaki, O., \& Martin, R. 2005. From ideal to real: A longitudinal study of the role of implicit leadership theories on leader-member exchanges and employee outcomes. Journal of Applied Psychology, 90: 659676.

Farrell, A. D. 1994. Structural equation modeling with longitudinal data: Strategies for examining group differences and reciprocal relationships. Journal of Consulting and Clinical Psychology, 62: 477487.

Foa, U. G., \& Foa, E. B. 1980. Resource theory: Interpersonal behavior as exchange. In K. J. Gergen, M. S. Greenberg \& R. H. Willis (Eds.), Social exchange: Advances in theory and research: 77-94. New York: Plenum.

Folger, R., \& Konovsky, M. A. 1989. Effects of procedural and distributive justice on reactions to pay raise decisions. Academy of Management Journal, 32: 115-130.

Frazier, M. L., Johnson, P. D., Gavin, M., Gotty, J., \& Snow, D. B. 2010. Organizational justice, trustworthiness, and trust: A multifoci examination. Group and Organization Management, 35: 39-76.

Gabarro, J. J., \& Athos, J. 1976. Interpersonal relations and communications. Englewood Cliffs, NJ: Prentice-Hall.

George, J. M., \& Jones, G. R. 2000. The role of time in theory and theory building. Journal of Management, 26: 657-684.

Gouldner, A. W. 1960. The norm of reciprocity: A preliminary statement. American Sociological Review, 25: 161-178.

Greenberg, J. 1987. A taxonomy of organizational justice theories. Academy of Management Review, 12: $9-22$.

Greenberg, J. 1993. The social side of fairness: Interpersonal and informational classes of organizational justice. In R. Cropanzano (Ed.), Justice in the workplace: Approaching fairness in human resource management: 79-103. Hillsdale, NJ: Erlbaum.

Kernan, M. C., \& Hanges, P. J. 2002. Survivor reactions to reorganization: Antecedents and consequences of procedural, interpersonal, and informational justice. Journal of Applied Psychology, 87: 916928.

Kim, W. C., \& Mauborgne, R. A. 1993. Procedural justice, attitudes, and subsidiary top management compliance with multinationals' corporate strategic decisions. Academy of Management Journal, 36: 502526.

Kline, R. B. 2005. Principles and practice of structural equation modeling. New York: Guilford.

Konovsky, M. A., \& Pugh, S. D. 1994. Citizenship behavior and social exchange. Academy of Management Journal, 37: 656-669.

Korsgaard, M. A., Sapienza, H. J., \& Schweiger, D. M. 2002. Beaten before begun: The role of procedural justice in planning change. Journal of Management, 28: 497516.

Korsgaard, M. A., Schweiger, D. M., \& Sapienza, H. J. 1995. Building commitment, attachment, and trust 
in strategic decision-making teams: The role of procedural justice. Academy of Management Journal, 38: $60-84$.

Lee, K., \& Allen, N. J. 2002. Organizational citizenship behavior and workplace deviance: The role of affect and cognitions. Journal of Applied Psychology, 87: 131-142.

Leventhal, G. S. 1976. The distribution of rewards and resources in groups and organizations. In L. Berkowitz \& W. Walster (Eds.), Advances in experimental social psychology, vol. 9: 91-131. New York: Academic Press.

Leventhal, G. S. 1980. What should be done with equity theory? New approaches to the study of fairness in social relationships. In K. Gergen, M. Greenberg \& R. Willis (Eds.), Social exchange: Advances in theory and research: 27-55. New York: Plenum.

Lewicki, R. J., \& Bunker, B. B. 1995. Trust in relationships: A model of development and decline. In B. B. Banker \& J. Z. Rubin (Eds.), Conflict, cooperation, and justice: 133-173. San Francisco: Jossey-Bass.

Lewicki, R. J., Wiethoff, C., \& Tomlinson, E. C. 2005. What is the role of trust in organizational justice? In J. Greenberg \& J. A. Colquitt (Eds.), Handbook of organizational justice: 247-270. Mahwah, NJ: Erlbaum.

Lind, E. A. 2001. Fairness heuristic theory: Justice judgments as pivotal cognitions in organizational relations. In J. Greenberg \& R. Cropanzano (Eds.), Advances in organizational justice: 56-88. Stanford, CA: Stanford University Press.

Lind, E. A., \& Tyler, T. R. 1988. The social psychology of procedural justice. New York: Plenum.

Lind, E. A., Tyler, T. R., \& Huo, Y. J. 1997. Procedural context and culture: Variation in the antecedents of procedural justice judgments. Journal of Personality and Social Psychology, 73: 767-780.

Mayer, R. C., \& Davis, J. H. 1999. The effect of the performance appraisal system on trust for management: A field quasi-experiment. Journal of Applied Psychology, 84: 123-136.

Mayer, R. C., Davis, J. H., \& Schoorman, F. D. 1995. An integrative model of organizational trust. Academy of Management Review, 20: 709-734.

Mayer, R. C., \& Gavin, M. B. 2005. Trust in management and performance: Who minds the shop while the employees watch the boss? Academy of Management Journal, 48: 874-888.

McAllister, D. J. 1995. Affect- and cognition-based trust as foundations for interpersonal cooperation in organizations. Academy of Management Journal, 38: 24-59.

Milkovich, G. T., \& Newman, J. M. 2002. Compensation. New York: Irwin/McGraw-Hill.
Mowday, R. T., Steers, R. M., \& Porter, L. W. 1979. The measurement of organizational commitment. Journal of Vocational Behavior, 14: 224-247.

Nyhan, R. C., \& Marlowe, H. A. 1997. Development and psychometric properties of the organizational trust inventory. Education Review, 21: 614-635.

Organ, D. W. 1990. The motivational basis of organizational citizenship behavior. In L. L. Cummings \& B. M. Staw (Eds.), Research in organizational behavior, vol. 12: 43-72. Greenwich, CT: JAI.

Pillai, R., Schriesheim, C. A., \& Williams, E. S. 1999. Fairness perceptions and trust as mediators for transformational and transactional leadership: A twosample study. Journal of Management, 25: 897-933.

Pillai, R., Williams, E. S., \& Tan, J. J. 2001. Are the scales tipped in favor of procedural or distributive justice? An investigation of the U.S., India, Germany, and Hong Kong (China). International Journal of Conflict Management, 12: 312-332.

Podsakoff, P. M., MacKenzie, S. B., Lee, J. Y., \& Podsakoff, N. P. 2003. Common method biases in behavioral research: A critical review of the literature and recommended remedies. Journal of Applied Psychology, 88: 879-903.

Roberts, K. H., \& O’Reilly, C. A. 1974. Measuring organizational communication. Journal of Applied Psychology, 59: 321-326.

Robinson, S. L. 1996. Trust and breach of the psychological contract. Administrative Science Quarterly, 41: $574-599$.

Rousseau, D. M., Sitkin, S. B., Burt, R. S., \& Camerer, C. 1998. Not so different after all: A cross-discipline view of trust. Academy of Management Review, 23: 393-404.

Rupp, D. R., \& Cropanzano, R. 2002. The mediating effects of social exchange relationships in predicting workplace outcomes from multifoci organizational justice. Organizational Behavior and Human Decision Processes, 89: 925-946.

Scholl, R. W., Cooper, E. A., \& McKenna, J. F. 1987. Referent selection in determining equity perceptions: Differential effects on behavioral and attitudinal outcomes. Personnel Psychology, 40: 113-124.

Schoorman, F. D., Mayer, R. C., \& Davis, J. H. 2007. An integrative model of organizational trust: Present, past, and future. Academy of Management Review, 32: $344-354$.

Schwab, D. P. 1980. Construct validity in organizational behavior. In L. L. Cummings \& B. M. Staw (Eds.), Research in organizational behavior, vol. 2: 3-43. Greenwich, CT: JAI.

Skarlicki, D. P., \& Latham, G. P. 2005. How can training be used to foster organizational justice? In J. Greenberg \& J. A. Colquitt (Eds.), Handbook of 
organizational justice: 499-522. Mahwah, NJ: Erlbaum.

Stinglhamber, F., De Cremer, D., \& Mercken, L. 2006. Perceived support as a mediator of the relationship between justice and trust. Group and Organization Management, 31: 442-468.

Stone-Romero, E. F. 1994. Construct validity issues in organizational behavior research. In J. Greenberg (Ed.), Organizational behavior: The state of the science: 155-179. Hillsdale, NJ: Erlbaum.

Thibaut, J., \& Walker, L. 1975. Procedural justice: $A$ psychological analysis. Hillsdale, NJ: Erlbaum.

Tyler, T. R. 1989. The psychology of procedural justice: A test of the group-value model. Journal of Personality and Social Psychology, 57: 830-838.

Tyler, T. R. 1994. Psychological models of the justice motive: Antecedents of distributive justice and procedural justice. Journal of Personality and Social Psychology, 67: 850-863.
Tyler, T. R., Degoey, P., \& Smith, H. 1996. Understanding why the justice of group procedures matters: A test of the psychological dynamics of the group value model. Journal of Personality and Social Psychology, 70: 913-930.

Tyler, T. R., \& Lind, E. A. 1992. A relational model of authority in groups. In M. P. Zanna (Ed.), Advances in experimental social psychology, vol. 25: 115191. San Diego: Academic Press.

Van den Bos, K. 2001. Fairness heuristic theory: Assessing the information to which people are reacting has a pivotal role in understanding organizational justice. In S. Gilliland, D. Steiner \& D. Skarlicki (Eds.), Theoretical and cultural perspectives on organizational justice: 63-84. Greenwich, CT: Information Age.

Van den Bos, K., Wilke, H. A. M., \& Lind, E. A. 1998. When do we need procedural fairness? The role of trust in authority. Journal of Personality and Social Psychology, 75: 1449-1458.
Jason A. Colquitt (colq@uga.edu) is the William Harry Willson Distinguished Chair in the Department of Management at the University of Georgia's Terry College of Business. He received his Ph.D. from Michigan State University's Eli Broad Graduate School of Management. His research interests include organizational justice, trust, team effectiveness, and personality influences on task and learning performance.
Jessica B. Rodell (jrodell@uga.edu) is an assistant professor in the Department of Management at the University of Georgia's Terry College of Business. She earned a Ph.D. and an MBA from the University of Florida's Warrington College of Business Administration. Her research interests include volunteering, organizational justice, and emotions.

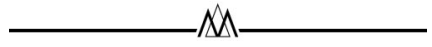

This article continues on the next page with Appendix A. 


\section{APPENDIX A}

\section{Trust Scales Used in Past Research on Justice and Trust}

\begin{tabular}{|c|c|c|}
\hline $\begin{array}{l}\text { Developers of } \\
\text { Measure }\end{array}$ & Items & Studies Using Measure \\
\hline $\begin{array}{l}\text { Roberts and O'Reilly } \\
\text { (1974) }\end{array}$ & $\begin{array}{l}\text { 1. How free do you feel to discuss with your immediate supervisor the } \\
\text { problems and difficulties in your job without jeopardizing your } \\
\text { position or having it held against you? } \\
\text { 2. Immediate supervisors at times must make decisions, which seem to } \\
\text { be against the interest of subordinates. When this happens to you as a } \\
\text { subordinate, how much trust do you have that your immediate } \\
\text { supervisor's decision was justified by other considerations? } \\
\text { 3. To what extent do you have trust and confidence in your immediate } \\
\text { supervisor regarding his general fairness? }\end{array}$ & $\begin{array}{l}\text { - Folger and Konovsky (1989) } \\
\text { - Kim and Mauborgne (1993) } \\
\text { - Konovsky and Pugh (1994) } \\
\text { Korsgaard and Schweiger } \\
\text { (1995) } \\
\text { - Korsgaard (2002) } \\
\text { Cropanzano, Prehar, and Chen } \\
(2002)\end{array}$ \\
\hline $\begin{array}{l}\text { Gabarro and Athos } \\
\text { (1976) }\end{array}$ & $\begin{array}{l}\text { 1. I believe my supervisor has high integrity } \\
\text { 2. I can expect my supervisor to treat me in a consistent and predictable } \\
\text { fashion. } \\
\text { 3. My supervisor is not always honest and truthful. } \\
\text { 4. In general, I believe my supervisor's motives and intentions are good. } \\
\text { 5. I don't think my supervisor treats me fairly. } \\
\text { 6. My supervisor is open and upfront with me. } \\
\text { 7. I am not sure I fully trust my supervisor. }\end{array}$ & $\begin{array}{l}\text { - Aryee, Budhwar, and Chen } \\
(2002) \\
\text { - Begley, Lee, and Hui (2006) }\end{array}$ \\
\hline McAllister (1995) & $\begin{array}{l}\text { 1. We have a sharing relationship. We can both freely share our ideas, } \\
\text { feeling, and hopes. } \\
\text { 2. I can talk freely to my supervisor about difficulties I am having at } \\
\text { work and know that (s)he will want to listen. } \\
\text { 3. We would both feel a sense of loss if one of us transferred and we } \\
\text { could no longer work together. } \\
\text { 4. If I shared my problems with my supervisor, I know (s)he would } \\
\text { respond constructively and caringly. } \\
\text { 5. I would have to say that we have both made considerable emotional } \\
\text { investments in our working relationship. } \\
\text { 6. My supervisor approaches his/her job with professionalism and } \\
\text { dedication. } \\
\text { 7. Given my supervisor's track record, I see no reason to doubt his/her } \\
\text { competence and preparation for the job. } \\
\text { 8. I can rely on my supervisor not to make my job more difficult by } \\
\text { careless work. } \\
\text { 9. Most people, even those who aren't close friends with my supervisor, } \\
\text { trust and respect him/her as a coworker. } \\
\text { 10. Other work associates of mine who must interact with my supervisor } \\
\text { consider him/her to be trustworthy. } \\
\text { 11. If people knew more about my supervisor and his/her background, } \\
\text { they would be more concerned and monitor his/her performance more } \\
\text { closely. }\end{array}$ & $\begin{array}{l}\text { - Ambrose and Schminke (2003) } \\
\text { - Stinglhamber, De Cremer, and } \\
\text { Mercken (2006) }\end{array}$ \\
\hline $\begin{array}{l}\text { Nyhan and Marlowe } \\
\text { (1997) }\end{array}$ & $\begin{array}{l}\text { 1. My level of confidence that my supervisor is technically competent at } \\
\text { the critical elements of his/her job is } \\
\text { 2. My level of confidence that my supervisor will make well thought out } \\
\text { decisions about his/her job is } \\
\text { 3. My level of confidence that my supervisor will follow through on } \\
\text { assignments is } \\
\text { 4. My level of confidence that my supervisor has an acceptable level of } \\
\text { understanding of his/her job is } \\
\text { 5. My level of confidence that my supervisor will be able to do his or } \\
\text { her job in an acceptable manner is } \\
\text { 6. When my supervisor tells me something, my level of confidence that I } \\
\text { can rely on what they tell me is } \\
\text { 7. My confidence in my supervisor to do the job without other problems } \\
\text { is } \\
\text { 8. My level of confidence that my supervisor will think through what he } \\
\text { or she is doing on the job is } \\
\text { 9. My level of confidence that my supervisor will treat me fairly is } \\
\text { 10. The level of trust between supervisors and workers in this organiza- } \\
\text { tion is } \\
\text { 11. The level of trust between my supervisor and me is } \\
\text { 12. The degree to which I can depend on my supervisor is }\end{array}$ & $\begin{array}{l}\text { - Pillai, Schriesheim, and } \\
\text { Williams (1999) } \\
\text { - Pillai, Williams, and Tan } \\
\text { (2001) } \\
\text { - Aryee, Budhwar, and Chen } \\
\text { (2002) }\end{array}$ \\
\hline
\end{tabular}

